\title{
Electrical behavior of exploding copper wire in ambient air
}

Mario Oscar Barbaglia, and Gonzalo Rodriguez Prieto

Citation: Physics of Plasmas 25, 072108 (2018); doi: 10.1063/1.5020252

View online: https://doi.org/10.1063/1.5020252

View Table of Contents: http://aip.scitation.org/toc/php/25/7

Published by the American Institute of Physics

\section{PHYSICS TODAY}

MANAGER'S GUIDE

WHITEPAPERS
READ NOW

PRESENTED BY Multiphysics Simulation 


\title{
Electrical behavior of exploding copper wire in ambient air
}

\author{
Mario Oscar Barbaglia ${ }^{1, a)}$ and Gonzalo Rodriguez Prieto ${ }^{2}$ \\ ${ }^{1}$ Instituto de Física Arroyo Seco, IFAS (UNCPBA) and CIFICEN (UNCPBA-CICPBA-CONICET), Pinto 399, \\ 7000 Tandil, Argentina \\ ${ }^{2}$ Universidad de Castilla-la Mancha, I.N.E.I., Campus Universitario de Ciudad Real s/n, 13071 Ciudad Real, \\ Spain
}

(Received 21 December 2017; accepted 23 June 2018; published online 11 July 2018)

\begin{abstract}
This work experimentally investigates the electrical behavior of an exploding wire when the initial energy of the system varies from 28 to $709 \mathrm{~J}$. This experiment uses 50 - $\mu$ m-diameter, 33-mm-long copper wires. The wire is surrounded by air at normal atmospheric pressure and temperature. The experiment monitored the current derivative, voltage between wire ends, total visible radiation emitted, and the shadow image of the wire to study how the electrical parameters vary as a function of initial energy. The results indicate a change in the initial discharge mechanism. Published by AIP Publishing. https://doi.org/10.1063/1.5020252
\end{abstract}

\section{INTRODUCTION}

Exploding wire experiments have relevance in several fields of science, such as inertial confinement fusion, ${ }^{1}$ nanopowder preparation, ${ }^{2-9}$ and basic science, ${ }^{10-14}$ to name but a few. The phenomenon begins with the release of energy stored in a capacitor bank through a conducting wire, several $\mu \mathrm{m}$ in radius and a few $\mathrm{cm}$ long. As a consequence of this energy, a plasma channel forms and persists for several microseconds until its impedance grows to the point that the current stops. The wire undergoes phase transitions from solid to liquid, liquid to gas, and gas to plasma. The duration of each stage depends on the system's configuration and on the energy delivered to the wire. The books by Chace and Moore $^{15-17}$ are a good introduction to the phenomenology of the problem. Recent investigations ${ }^{18}$ studied parametrically the outward shock wave generated during the wire explosion for wire diameters from 50 to $500 \mu \mathrm{m}$ and for a loading capacitor bank with voltages ranging from 5 to $25 \mathrm{kV}$. The initial wire stage was studied by Tkachenko et al. ${ }^{19}$ and Hammer and Sinars ${ }^{20}$ among others, whereas the rate of energy deposition was investigated by Sarkisov et al., ${ }^{21}$ Sinars et al., ${ }^{22}$ and Sahoo et al. ${ }^{23}$ Finally, Clark et al. ${ }^{24}$ showed the different types of initial phase behavior in exploding wire experiments.

The present work uses 50- $\mu$ m-diameter, 33-mm-long wires to investigate their electrical characteristics in exploding wire experiments as a function of the loading voltage of the capacitor bank.

\section{EXPERIMENT}

This experiment used the so-called ALEX device at the Institute for Energy Research (INEI) at the University of Castilla-La Mancha, Spain. This small exploding wire device can store up to $709 \mathrm{~J}$. Figure 1 shows the electrical diagram. The device consists of a $2.27 \mu \mathrm{F}$ capacitor bank $C$, stray inductances represented by $L 1$ and $L 2$ with $L 1+L 2=142$ $\mathrm{nH}$, a stray resistance $R$, and a spark gap $S-G$ that controls

\footnotetext{
${ }^{\text {a) }}$ mario.barbaglia@gmail.com
}

the energy discharge. The spark gap is triggered by a $30 \mathrm{~ns}$, $100 \mathrm{kV}$ pulse. The wire is surrounded by air at normal atmospheric pressure and temperature. This copper wire is $50 \mu \mathrm{m}$ in diameter and $33 \mathrm{~mm}$ long. The distance between the wire and the ground plane is $130 \mathrm{~mm}$.

In the schematic, the wire to be analyzed is represented by an impedance $Z E W$ because, in the first stage, it is dominated by a resistive behavior whereas later, after the explosion, it is mainly inductive. The capacitors can store an initial voltage up to $25 \mathrm{kV}$, which allows us to observe and characterize the behavior of the metallic wire over a broad range of energies. The current derivative history was measured by using a calibrated Rogowski coil, labeled $d i / d t$ in Fig. 1. The voltage drop across the wire was measured by using two calibrated fast resistive dividers labeled $V 1$ and $V 2$ in Fig. 1. The light emitted by the system was collected by a naked fast photodetector (Thorlab DET210 with a rise and fall time of $1 \mathrm{~ns}$ and a spectral response greater than $25 \%$ of the maximum responsivity between 400 and $950 \mathrm{~nm}$ ). The current was determined by the numerical integration of the current derivative. Shadowgraphs were collected by using the system described by Barbaglia and Prieto. ${ }^{18}$

\section{RESULTS}

Figure 2 shows typical waveforms recorded during the experiment for $10 \mathrm{kV}$ in the capacitor bank. From top to bottom are shown the current derivative, the voltage $V 1$, the voltage $V 2$, the photodetector signal, the circulating system current, and the "dark current" as a function of the time.

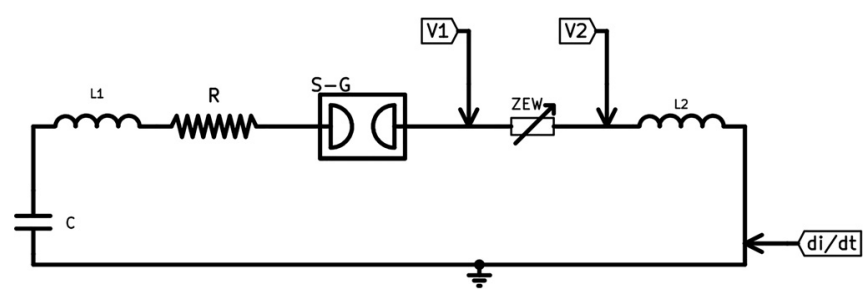

FIG. 1. Electrical schematic of exploding wire system. 


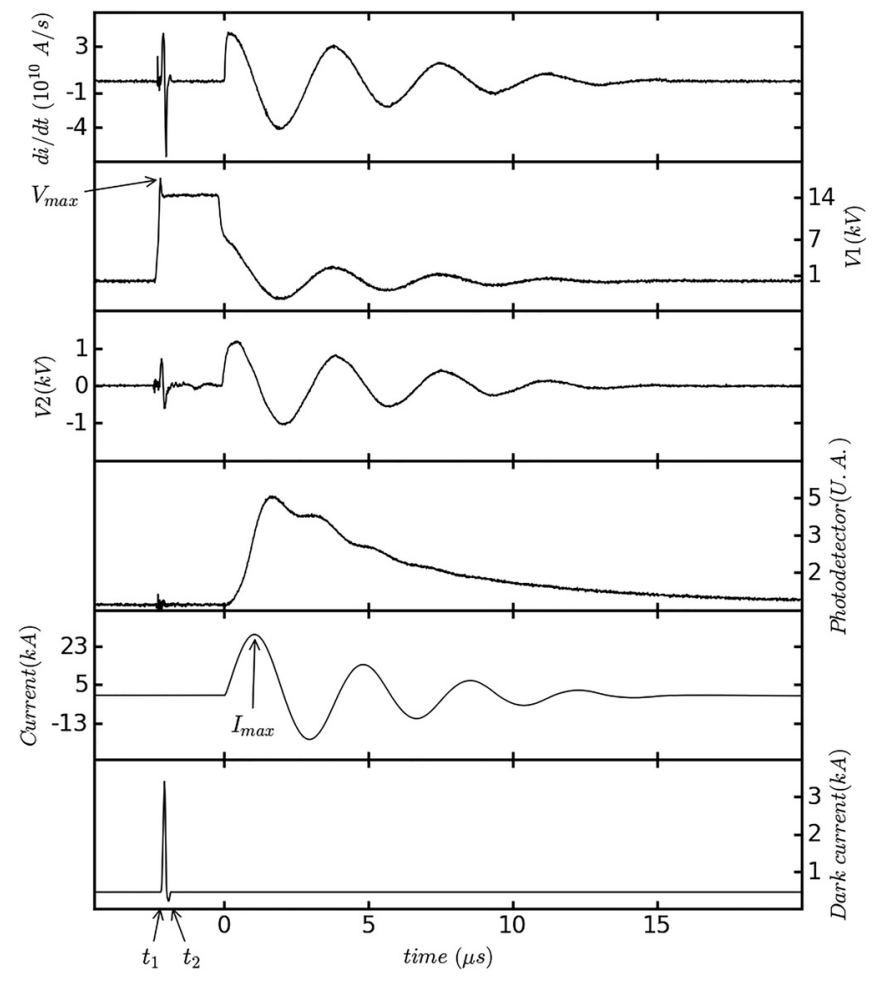

FIG. 2. Typical waveforms from an exploding wire experiment. Here, the capacitor bank was charged at $10 \mathrm{kV}$. The time origin is taken to be the moment when the current is established after the dark zone. $I_{\max }$ and $V_{\max }$ indicate the maximum current and the maximum voltage in the dark zone, respectively.

Figure 3 shows the shadowgraph for this experiment. In this work, we measured the derivative of the current flowing through the entire circuit and we distinguish two different types of current: The first type of current flows at the onset of the phenomenon, which we call "dark current" (this is the current during the "dark pause" stage of the wire). The second type of current, which we simply we call "current," flows during the plasma stage.

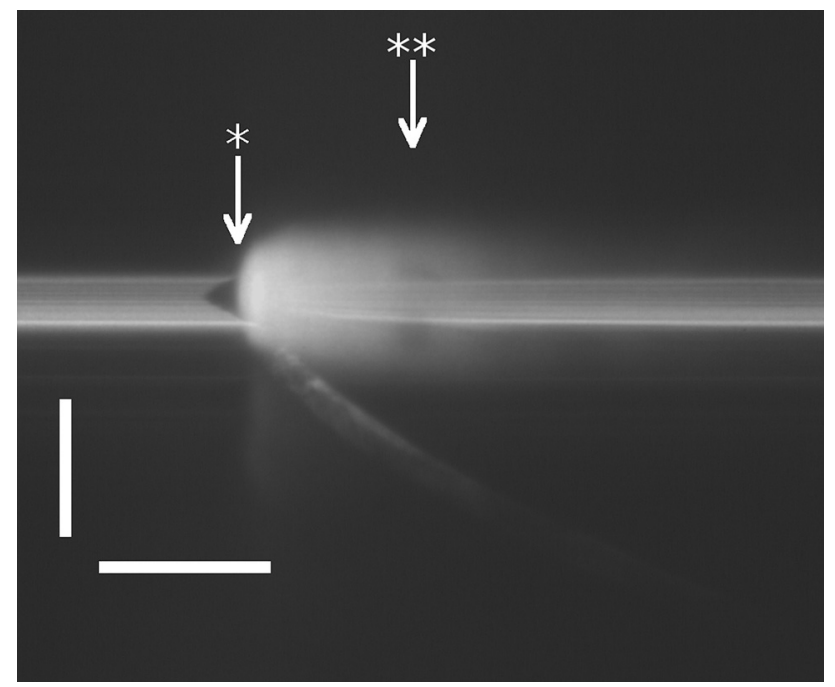

FIG. 3. Typical shadowgraph of an exploding wire when the initial capacitor bank voltage is $10 \mathrm{kV}$. Horizontal mark corresponds to $10 \mu \mathrm{s}$ and vertical mark is $10 \mathrm{~mm}$. The electrical signals recorded in this experiment are shown in Fig. 2. The asterisk indicates time $t=0$, and the double asterisk indicates $t=10 \mu$ s according to Fig. 2 .
The experiment begins at $-2.3 \mu \mathrm{s}$, when the voltage $V 1$ is growing. After a short time, the voltage $V 1$ reaches a maximum $V_{\max }=17.3 \mathrm{kV}$; later $V 1$ decreases because the wire impedance decreases, which causes the current to increase, as shown in Fig. 2. The voltage $V 2$ is consistent with a normal voltage drop caused by the current flowing through the fixed inductance $L 2$. After $0.5 \mu \mathrm{s}$, the current is interrupted because the impedance of the wire increases, then the voltage $V 1$ remains constant and $V 2$ is near zero. At this point, the system emits no visible light, so the wire is said to be going through the "dark pause" or "dwell time," which ends at the time $t=0$. After the dark pause, the voltage $V 1$ drops, the current increases once again, and the plasma begins to be generated. With the onset of plasma, the system begins to radiate visible light, with the maximum emission occurring at $t=1.7 \mu \mathrm{s}$. At this stage, a plasma channel is established and the circuit is primarily inductive. The current continues flowing for $\sim 17 \mu$ s and then stops.

Figure 3 shows a shadowgraph corresponding to the signals shown in Fig. 2. Initially, a filament with the diameter of the solid wire is observed, and later, a conical obscure zone appears, which is the so-called "dark zone." In the dark zone, the wire particles lose continuity and move apart, increasing the impedance. After the dark zone appears, which is marked by the asterisk in Fig. 3, the current increases because the wire has evolved into a plasma channel, thereby diminishing the impedance. This physical event was used to synchronize the electrical signals and the shadowgraph, setting the time origin $t=0$ at the point where the current begins to increase after the dark zone and where the dark zone terminates in the shadowgraph. Note the appearance of the shock wave generated by the system, ${ }^{11,25-29}$ which was the subject of previous investigations. ${ }^{18}$

Figure 4 shows that the maximum current $I_{\max }$ in the system is linear with the initial voltage of the capacitor bank. In the particular case of Fig. 2, this maximum occurs at $1 \mu \mathrm{s}$, as expected for a circuit constituted by a series of resistors, inductors, and capacitors where the components are not anomalous, as is the case once the plasma has been created. Furthermore, the plasma resistivity and inductance constitute a very small part of the total resistivity and inductance of the total circuit.

Figure 5 shows the maximum dark-zone voltage $V_{\max }$ between the wire ends as a function of the initial voltage of the capacitor bank. In the particular experiment of Fig. 2, this voltage occurs at $-2.2 \mu \mathrm{s}$. The data show that $V_{\max }$ is essentially linear with the initial voltage of the capacitor bank up to $20 \mathrm{kV}$ (with slope of $1.4 \mathrm{kV} / \mathrm{kV}$ ), at which point a plateau is reached.

Figure 6 shows the time $T_{V \max }$ at which the maximum voltage occurs between the wire ends in the dark zone as a function of the initial capacitor bank voltage. Combining these results with those of Fig. 5 indicates that, as the initial voltage in the capacitor bank increases, $T_{V \max }$ decreases and $V_{\text {max }}$ increases.

We now consider the maximum radius $R_{\max }$ (at $t={ }^{-} 0$ ) of the cylindrical wire in the dark zone, which decreases quadratically with the initial capacitor voltage, as shown in 


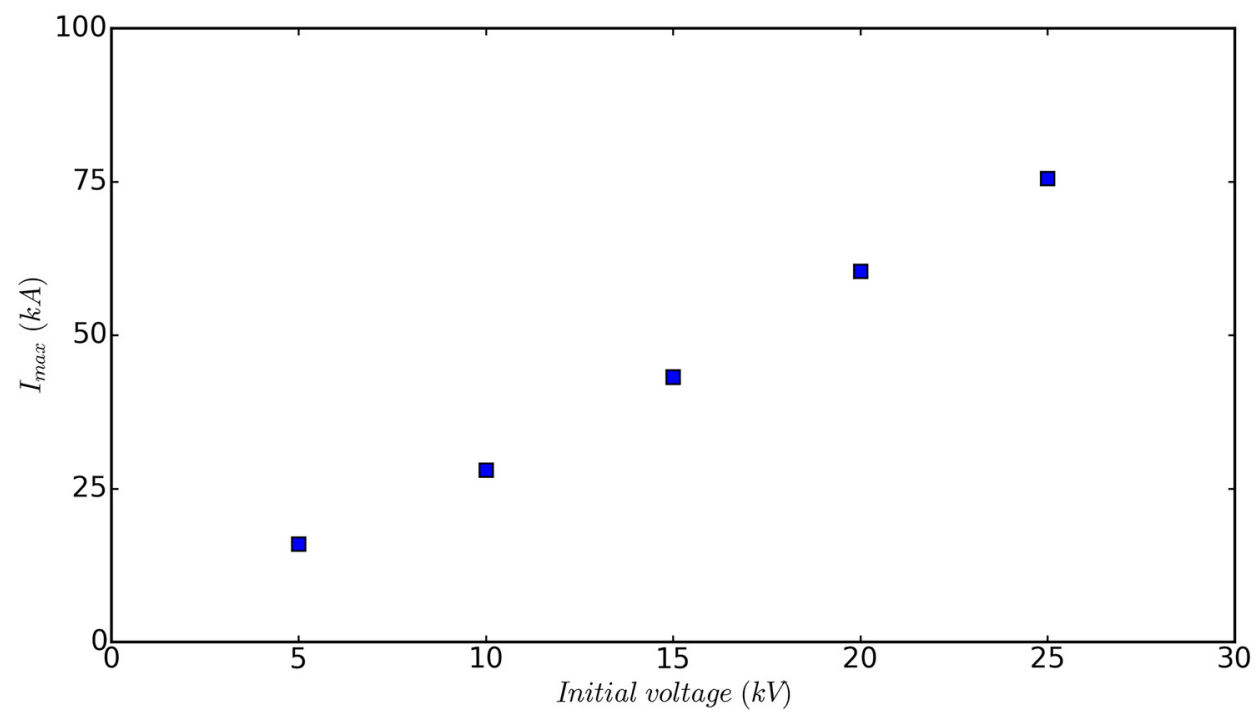

FIG. 4. Maximum current $I_{\max }$ as a function of initial voltage of capacitor bank.

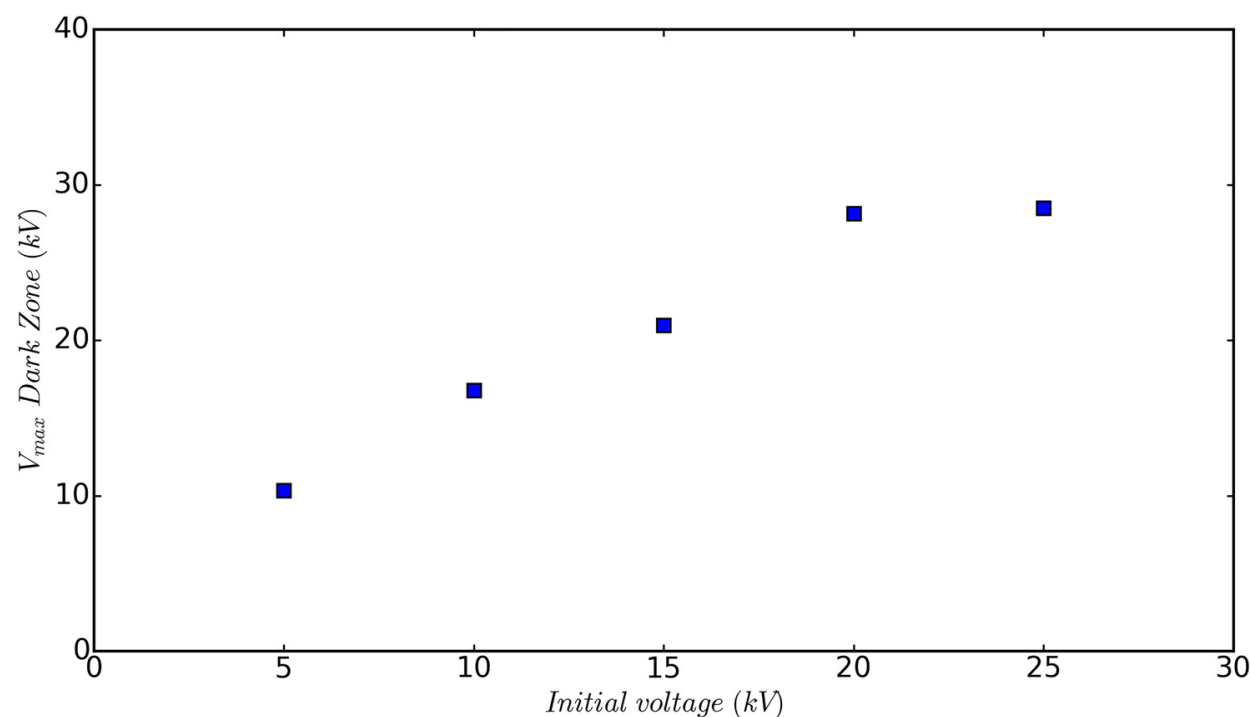

FIG. 5. Maximum voltage over wire as measured in the dark zone as a function of the initial voltage of capacitor bank.

Fig. 7. The initial wire radius is $25 \mu \mathrm{m}$, so the radius amplification varies from 24 to 75 .

Figure 8 shows the duration of the dark zone, $T_{\text {DarkZone, }}$ as a function of initial voltage on the capacitors. For the specific case shown in Fig. $2, T_{\text {DarkZone }}=2.3 \mu \mathrm{s}$. This time varies inversely with the initial voltage on the capacitors. Vlastós explored this topic ${ }^{30}$ for thin wires made of constantan or tungsten.

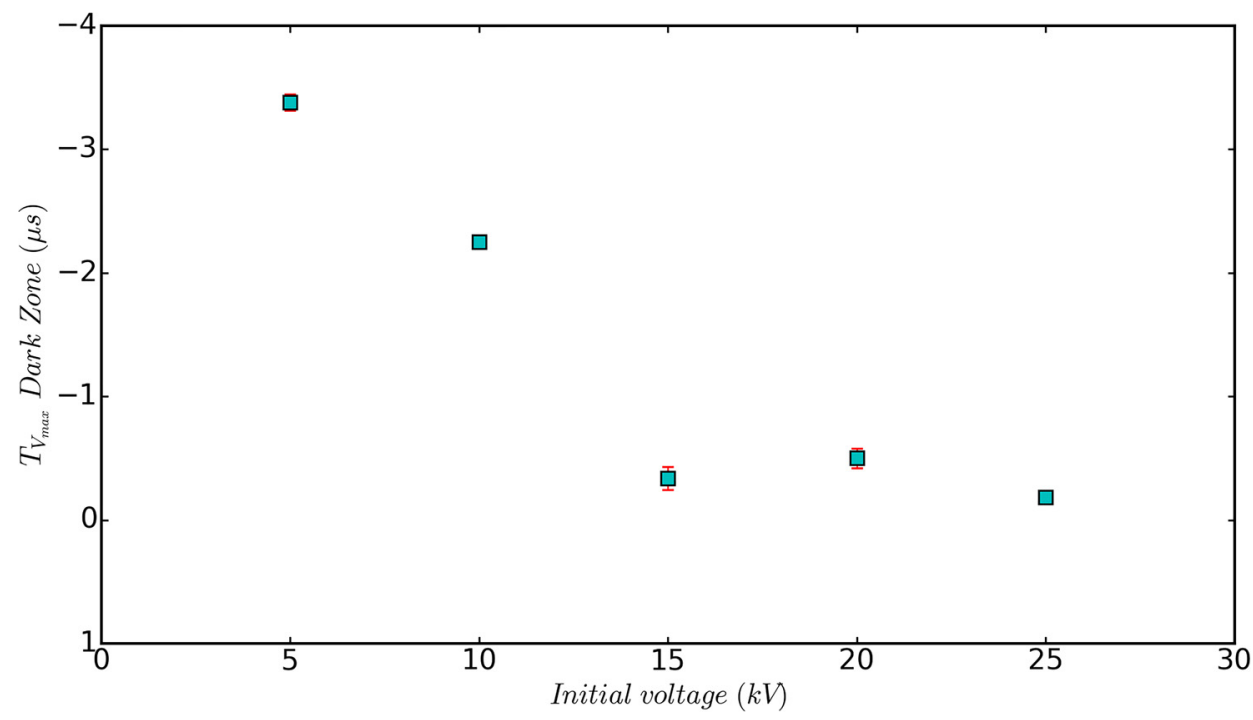

FIG. 6. Time at which maximum voltage $V_{\max }$ in attained in the dark zone as a function of the initial voltage of the capacitor bank. 


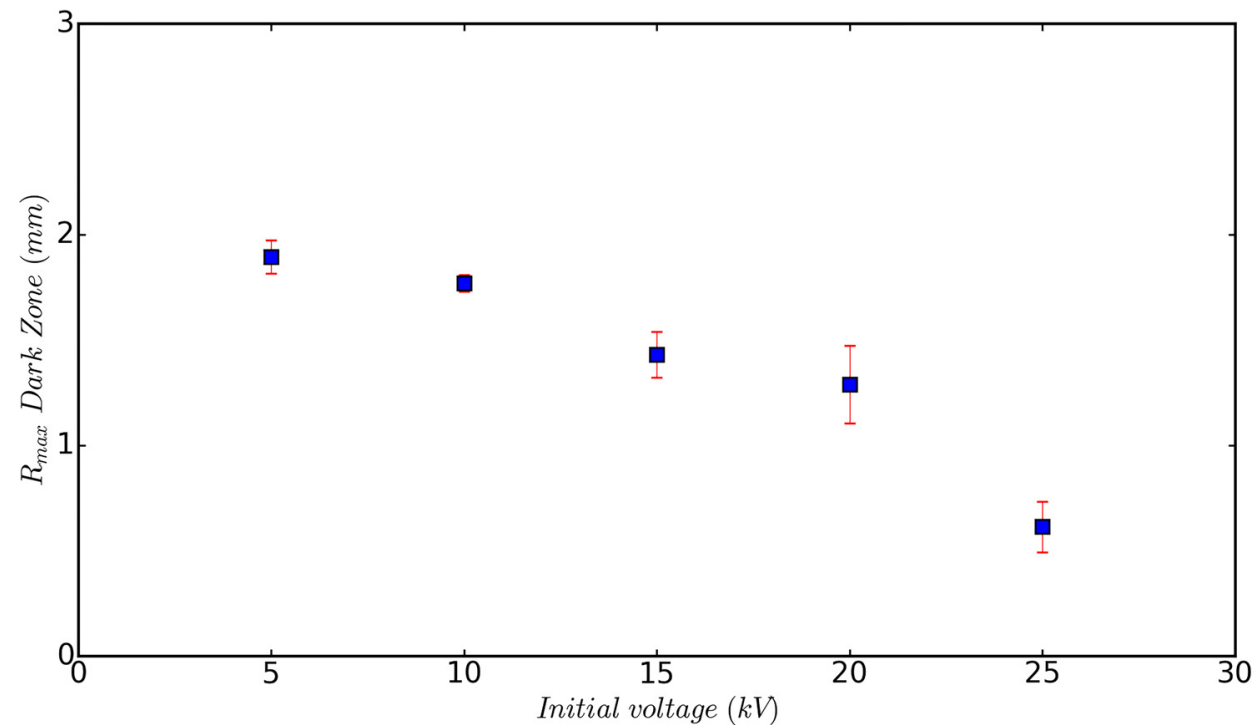

FIG. 7. Maximum radius $R_{\max }$ of dark zone as a function of initial voltage of capacitor bank.
Figure 9 shows the maximum electrical energy delivered to the dark zone. The data could be fit to a quadratic function up to $20 \mathrm{kV}$, above which $E_{\max }$ remains constant. The energy delivered to the dark zone is calculated by using

$$
E_{\text {dark zone }}=\int_{t_{1}}^{t_{2}}[V 1(t)-V 2(t)] i(t) d t,
$$

where $t_{1}$ and $t_{2}$ are the onset and ending times of the dark zone current, respectively (cf. Fig. 2).

The photodetector detects the radiation emitted between 400 and $950 \mathrm{~nm}$. The maximum emission occurs at $1.7 \mu \mathrm{s}$ for the experiment of Fig. 2. This emission correlates with the existence of the plasma channel after the dark zone. Figure 10 shows that the maximum emission is linear with the initial voltage of the capacitor bank (with a slope of $53 \mathrm{kV}^{-1}$ ).

Figure 11 shows the plasma-channel radius as a function of the maximum current in the system. The plasma-channel radius was measured at the same time $(t=10 \mu \mathrm{s})$ in all configurations (this time was selected arbitrarily). The data show an increase in the plasma radius with current, with a maximum radius of $10 \mathrm{~mm}$ achieved for a current of $75 \mathrm{kA}$.
Determining the temporal evolution of the wire phase requires evaluating the thermodynamic conditions of the system, as done in previous studies. ${ }^{13,31-33}$ Although a precise calculation is beyond the scope of the present work, a rather crude estimate may be obtained by considering the properties of copper summarized in Table I. The energies $E_{1}$ and $E_{\mathrm{V}}$ required to liquefy and vaporize the wire are

$$
\begin{gathered}
E_{l}=V \rho\left[S_{H}\left(T_{m p}-T_{A}\right)+L_{h f}\right], \\
E_{v}=E_{l}+V \rho\left[S_{H}\left(T_{b p}-T_{m p}\right)+L_{h v}\right],
\end{gathered}
$$

respectively, where $V$ is the wire volume, $T_{\mathrm{A}}$ is the ambient temperature $(298 \mathrm{~K}), S_{\mathrm{H}}$ is the copper specific heat, $\rho$ is the solid density, $L_{\mathrm{hf}}$ is the latent heat of fusion, $L_{\mathrm{hv}}$ is the latent heat of vaporization, and $T_{\mathrm{mp}}$ and $T_{\mathrm{bp}}$ are the melting and boiling temperatures, respectively. By evaluating Eqs. (1) and (2), we obtain $E_{1}=0.06 \mathrm{~J}$ and $E_{\mathrm{V}}=2.5 \mathrm{~J}$, which is less than the maximum energy measured in the dark zone in Fig. 9.

Earlier, Vlastós ${ }^{30}$ measured the dwell time as a function of the initial voltage of the capacitor bank for wires of constantan and tungsten. Figure 8 reports similar measurements for copper wires. Note that, at $20 \mathrm{kV}$, the discharge

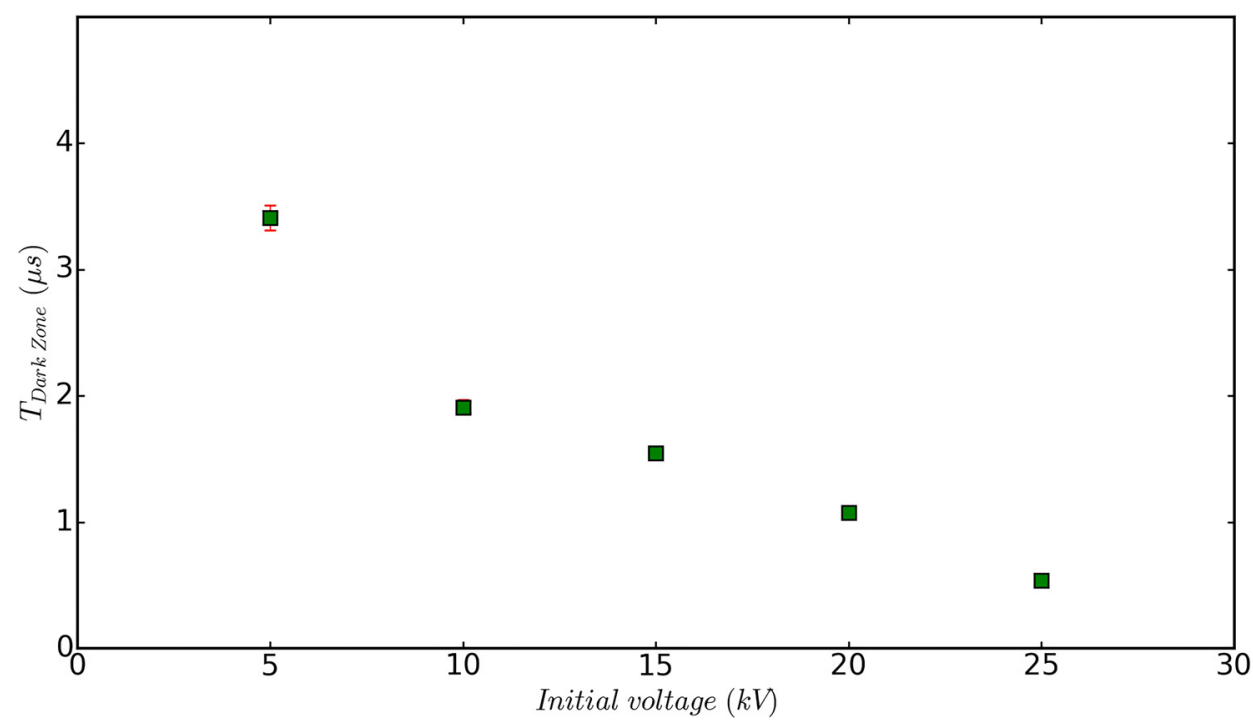

FIG. 8. Duration $T_{\text {DarkZone }}$ of dark zone as a function of initial voltage of capacitor bank. 

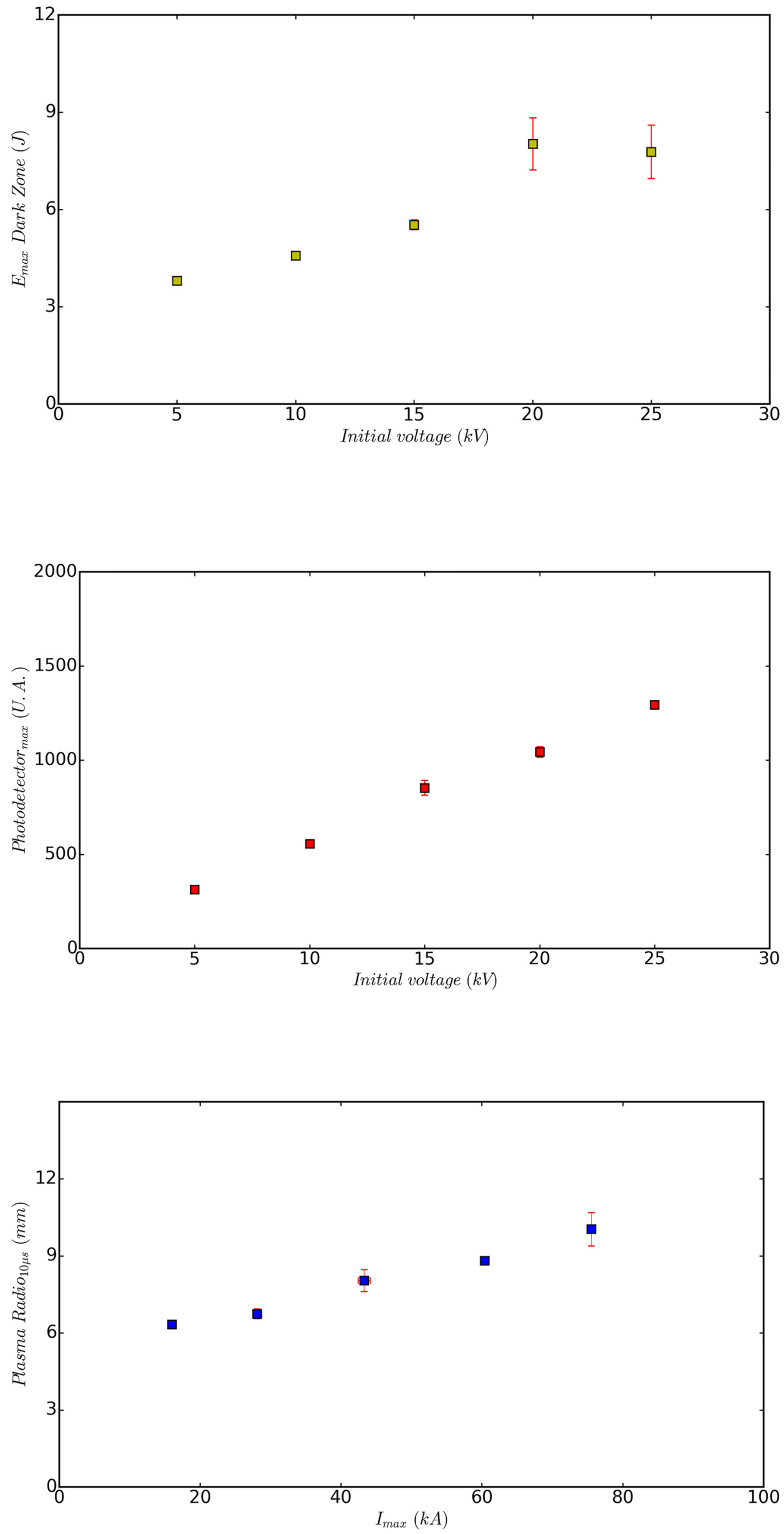

FIG. 9. Maximum energy $E_{\max }$ in the dark zone as a function of initial voltage of capacitor bank.

FIG. 10. Maximum intensity of radiation emitted (from 400 to $950 \mathrm{~nm}$ ) as a function of initial voltage of capacitor bank.
FIG. 11. Plasma channel radius at $10 \mu \mathrm{s}$ as a function of maximum current in system. 
TABLE I. Properties of copper.

\begin{tabular}{lcc}
\hline \hline Copper & & \\
\hline Density $(\boldsymbol{\rho})$ & 8920000 & $\mathrm{~g} / \mathrm{m}^{3}$ \\
Specific heat $\left(\boldsymbol{S}_{\boldsymbol{H}}\right)$ & 0.385 & $\mathrm{~J} / \mathrm{g} \mathrm{K}$ \\
Melting point $\left(\boldsymbol{T}_{\boldsymbol{m} \boldsymbol{p}}\right)$ & 1357.77 & $\mathrm{~K}$ \\
Boiling point $\left(\boldsymbol{T}_{\boldsymbol{b} \boldsymbol{p}}\right)$ & 2835 & $\mathrm{~K}$ \\
Latent heat of fusion $\left(\boldsymbol{L}_{\boldsymbol{h} \boldsymbol{f}}\right)$ & 209 & $\mathrm{~J} / \mathrm{g}$ \\
Latent heat of vaporization $\left(\boldsymbol{L}_{\boldsymbol{h} \boldsymbol{v}}\right)$ & 4730 & $\mathrm{~J} / \mathrm{g}$ \\
\hline \hline
\end{tabular}

mechanisms change from internal to external, ${ }^{17}$ which is supported by the data shown in Fig. 5 where the voltage on the wire does not increase as would be expected but reaches a maximum at $V I=28 \mathrm{kV}$. In addition, the energy in the dark zone at $25 \mathrm{kV}$ is similar to that at $20 \mathrm{kV}$ (see Fig. 9). It thus follows that, for $50-\mu \mathrm{m}$-diameter, 33 -mm-long copper wires, the minimum electric field required to produce an internal discharge is $6 \mathrm{kV} / \mathrm{cm}$.

The light detected by the photodetector originates mainly in the plasma channel created after the explosion because the photodetector signal (see Fig. 10) is linearly correlated with the plasma radius (see Fig. 11), provided that the channel is fully developed at $10 \mu \mathrm{s}$.

Previous work (see Fig. 3 of Barbaglia and Prieto ${ }^{18}$ ) experimentally determined the increase in the outward shock-wave velocity with loading voltage of the capacitor bank. However, for a loading voltage of $25 \mathrm{kV}$, the dark zone cannot be resolved.

\section{CONCLUSIONS}

In this parametric study of an exploding wire system in air at normal temperature and atmospheric pressure, we investigate the passage of a wire discharge from internal to external based on electrical and photographic data. Furthermore, this change appears when the electric field along the wire exceeds $6 \mathrm{kV} / \mathrm{cm}$. The energy in the dark zone suffices to liquefy and vaporize the copper wire. In addition, the linear relationship between the system's initial energy (i.e., the initial voltage of the capacitor bank) and the maximum current flowing through the circuit indicates that the circuit behaves like a circuit with resistance, capacitance, and inductance in series. When the light emitted correlates linearly with the maximum current in the circuit, the data are linear with the initial voltage of the capacitor bank, in accordance with the emission produced by a fully ionized plasma; also, the plasma radius increases when the current increases. The so-called "dark zone" increases when the initial voltage of the capacitor bank decreases, thereby delaying plasma formation, which is an important consideration for designing explosives, switches, and other devices.

\section{ACKNOWLEDGMENTS}

This work has been partially supported by the Ministerio de Economía y Competitividad of Spain (Grant No. ENE2016-75703-R), "Consejo Nacional de Investigaciones
Científicas y Técnicas" (CONICET), and by the "Fondo para la Investigación Científica y Tecnológica" (FONCyT) of Argentina. The authors thank R. Piriz and M. Milanese for comments and suggestions.

${ }^{1}$ V. L. Kantsyrev, A. S. Chuvatin, A. S. Safronova, L. I. Rudakov, A. A. Esaulov, A. L. Velikovich, I. Shrestha, A. Astanovitsky, G. C. Osborne, V. V. Shlyaptseva, M. E. Weller, S. Keim, A. Stafford, and M. Cooper, Phys. Plasmas 21, 31204 (2014).

${ }^{2}$ L. H. Bac, B. K. Kim, J. S. Kim, and J. C. Kim, J. Magn. 16, 435 (2011).

${ }^{3}$ V. S. Sedoi and N. A. Yavorovsky, in Third International Forum on Strategic Technologies, IFOST 2008 (IEEE, 2008), pp. 220-225.

${ }^{4}$ L. H. Bac, G. S. Yun, J. S. Kim, H. S. Choi, and J. C. Kim, J. Nanosci. Nanotechnol. 11, 1730 (2011)

${ }^{5}$ A. Abdullah and S. Annapoorni, Pramana 65, 815 (2005).

${ }^{6}$ I. V. Beketov, A. P. Safronov, A. I. Medvedev, J. Alonso, G. V. Kurlyandskaya, and S. M. Bhagat, AIP Adv. 2, 22154 (2012).

${ }^{7}$ C. Cho, Y. Kinemuchi, H. Suematsu, W. Jiang, and K. Yatsui, Jpn. J. Appl. Phys., Part 1 42, 1763 (2003).

${ }^{8}$ H. R. Humud, A. S. Wasfi, and A. M. Makia, Asian J. Appl. Sci. Eng. 3, 23 (2014).

${ }^{9}$ G. Kawamura, S. Alvarez, I. E. Stewart, M. Catenacci, Z. Chen, and Y.-C. Ha, Sci. Rep. 5, 18333 (2015).

${ }^{10}$ N. B. Volkov, E. A. Zhukova, S. I. Tkachenko, and K. V. Khischenko, in 14th International Symposium on High-Current Electronics (Tomsk, Russia, 2006), p. 5.

${ }^{11}$ S. I. Tkachenko, D. V. Barishpoltsev, G. V. Ivanenkov, V. M. Romanova, A. E. Ter-Oganesyan, A. R. Mingaleev, T. A. Shelkovenko, and S. A. Pikuz, Phys. Plasmas 14, 123502 (2007).

${ }^{12}$ A. Grinenko, Underwater Electrical Wire Explosion (Technion-Israel Institute of Technology, 2006).

${ }^{13}$ G. S. Sarkisov, S. E. Rosenthal, and K. W. Struve, Rev. Sci. Instrum. 78, 43505 (2007).

${ }^{14}$ F. D. Bennett, Phys. Fluids 1, 347 (1958).

${ }^{15}$ Exploding Wires, edited by W. G. Chace and H. K. Moore (Springer, Boston, 1995).

${ }^{16}$ W. G. Chace and H. K. Moore, Exploding Wires (Plenum Press, 1962), Vol. II.

${ }^{17}$ Exploding Wires, edited by W. G. Chace and H. K. Moore (Springer, Boston, 1968).

${ }^{18}$ M. Barbaglia and G. R. Prieto, Phys. Plasmas 23, 102706 (2016).

${ }^{19}$ S. I. Tkachenko, V. S. Vorob'ev, and S. P. Malyshenko, J. Phys. D: Appl. Phys. 37, 495 (2004)

${ }^{20}$ D. A. Hammer and D. B. Sinars, Laser Part. Beams 19, 377 (2001).

${ }^{21}$ G. S. Sarkisov, K. W. Struve, and D. H. McDaniel, Phys. Plasmas 11, 4573 (2004).

${ }^{22}$ D. B. Sinars, M. Hu, K. M. Chandler, T. A. Shelkovenko, S. A. Pikuz, J. B. Greenly, D. A. Hammer, and B. R. Kusse, Phys. Plasmas 8, 216 (2001).

${ }^{23}$ S. Sahoo, A. K. Saxena, T. C. Kaushik, and S. C. Gupta, High Energy Density Phys. 17(Part B), 270 (2015).

${ }^{24}$ G. L. Clark, J. J. Hickey, R. J. Kingsley, and R. F. Wuerker, Exploding Wires (Springer, 1962), pp. 175-180.

${ }^{25}$ F. D. Bennett, Phys. Fluids 5, 891 (1962).

${ }^{26}$ K. Kolacek, J. Schmidt, V. Prukner, P. Sunka, O. Frolov, J. Straus, and M. Martinkova, in Proceedings of the 2005 IEEE Pulsed Power Conference (IEEE, 2005), pp. 280-283.

${ }^{27}$ X. Li, Y. Chao, J. Wu, R. Han, H. Zhou, and A. Qiu, J. Appl. Phys. 118, 23301 (2015).

${ }^{28}$ L. P. Volkov, V. M. Voronov, and S. V. Samylov, Sov. J. Exp. Theor. Phys. 24, 8 (1967).

${ }^{29}$ S. Song, M. G. Kim, and U. Kim, in SPIE High Speed Photography, edited by M. L. Andre and M. Hugenschmidt (SPIE Press, Strasbourg, 1984), pp. 922-937.

${ }^{30}$ A. E. Vlastós, J. Appl. Phys. 44, 2193 (1973).

${ }^{31}$ G. R. Prieto, L. Bilbao, and M. Milanese, Laser Part. Beams 35, 26 (2017).

${ }^{32}$ F. D. Bennett, Phys. Fluids 7, 147 (1964).

${ }^{33}$ I. I. Beilis, A. Shashurin, R. B. Baksht, and V. Oreshkin, J. Appl. Phys. 105, 33301 (2009). 